\title{
PENGARUH STRATEGI PEMBELAJARAN KIMIA SMA BERBASIS PERCOBAAN AWAL TERHADAP HASIL BELAJAR SISWA PADA MATERI KOLOID
}

\author{
Ni Putu Radi Widayanti, I Wayan Subagia, I Nyoman Suardana \\ Universitas Pendidikan Ganesha \\ Singaraja, Indonesia \\ e-mail: radiwidayanti@yahoo.co.id, aigabus@yahoo.co.id, \\ suardana_sgr@yahoo.com
}

\begin{abstract}
Abstrak
Penelitian ini bertujuan untuk mendeskripsikan dan menjelaskan perbedaan hasil belajar antara siswa yang dibelajarkan dengan strategi pembelajaran kimia SMA berbasis percobaan awal dan strategi pembelajaran ekspositori terhadap hasil belajar siswa pada materi koloid di SMA Negeri 1 Baturiti. Jenis penelitian ini adalah penelitian eksperimen semu dengan menggunakan rancangan nonrandomized control group pretest-postest design. Populasi penelitian ini adalah siswa kelas XI IPA SMA Negeri 1 Baturiti tahun ajaran 2017/2018. Sampel penelitian ini adalah siswa kelas XI IPA 2 dan XI IPA 3. Data yang dikumpulkan berupa data hasil belajar pada aspek kognitif. Metode pengumpulan data yang digunakan adalah metode tes. Data dianalisis menggunakan statistik deskriptif dan inferensial dengan uji Anakova. Hasil penelitian menunjukkan bahwa terdapat perbedaan hasil belajar kimia koloid yang signifikan antara siswa yang dibelajarkan dengan antara strategi pembelajaran kimia SMA berbasis percobaan awal dan strategi pembelajaran ekspositori. Adanya perbedaan hasil belajar siswa menunjukkan bahwa pembelajaran menggunakan antara strategi pembelajaran kimia SMA berbasis percobaan awal pada materi koloid berpengaruh positif terhadap hasil belajar siswa di SMA Negeri 1 Baturiti.
\end{abstract}

Kata Kunci: strategi pembelajaran, percobaan awal, hasil belajar, koloid

\begin{abstract}
This study aimed to describe and explain the difference effect of starter experiment based learning strategy and expository learning strategy on colloidal topik toward students learning achievement in SMA Negeri 1 Baturiti. This study was quasi experiment, using nonrandomized kontrol group pretest-postest design. The population of this study was XI IPA students of SMA Negeri 1 Baturiti in academic year 2017/2018. The sample of this study was XI IPA 2 and XI IPA 3 class students. The data collected was in form of cognitive learning achievement. The method of collecting data was test method. The data obtained were analyzed by using descriptive and inferential statistics. The inferential statistics used was Anacova. The result of this study showed that there was a significant difference of learning achievement possessed by students who were taught by starter experiment based learning strategy compared to the students who were taught by expository learning strategy. The different
\end{abstract}


learning achievement shows that starter experiment based learning strategy has a positve effect on the chemistry learning achievement in SMA Negeri 1 Baturiti.

Keyword: starter experiment, learning strategy, chemistry learning achievement, colloid

\section{PENDAHULUAN}

Kurikulum yang berlaku juga menjadi landasan yang penting untuk menentukan strategi pembelajaran yang diterapkan di kelas. Prinsip pembelajaran yang digunakan dalam kurikulum 2013 antara lain: (1) peserta didik mencari tahu; (2) belajar berbasis aneka sumber belajar; (3) penggunaan pendekatan ilmiyah; (4) pembelajaran berbasis kompetensi; (5) pembelajaran terpadu; (6) pembelajaran dengan jawaban yang kebenarannya multi dimensial; (7) dari pembelajaran verbalisme menuju keterampilan aplikatif; (8) peningkatan dan keseimbangan antara keterampilan fisikal (hardskills) dan keterampilan mental (softskills); (9) pembelajaran yang berekspositori di rumah di sekolah, dan di masyarakat (Permendikbud Nomor 22 Tahun 2016). Salah satu prinsip penting dalam pembelajaran menurut kurikulum 2013 adalah penerapan pendekan ilmiah. Pendekatan ilmiah adalah proses pembelajaran yang dirancang sedemikian rupa agar peserta didik secara aktif mengonstruk konsep, hukum atau prinsip melalui tahapan-tahapan mengamati (untuk mengidentifikasi atau menemukan masalah), merumuskan masalah, mengajukan atau merumuskan hipotesis, mengumpulkan data dengan berbagai teknik, menganalisis data, menarik kesimpulan dan mengomunikasikan konsep, hukum atau prinsip yang ditemukan.

Prinsip-prinsip pembelajaran pada kurikulum 2013 secara keseluruhan menuntut untuk diterapkannya pembelajaran yang berpusat pada siswa. Strategi pembelajaran yang diterapkan juga harus memungkinkan siswa untuk mencari pengetahuan sebanyak-banyaknya dari berbagai jenis sumber belajar dan memotivasi siswa untuk belajar di rumah dan di lingkungan sekitarnya selain pendidikan formal di sekolah. Meski kurikulum telah menuntut dilaksanakannya pembelajaran yang berpusat pada siswa, nyatanya masih banyak guru yang masih menerapkan pembelajaran berpusat pada guru. Sari (2017) menyatakan bahwa selama ini pembelajaran masih menggunakan strategi pembelajaran konvensional, yang mana siswa hanya menerima informasi dari penjelasan guru. Selain itu Merta (2013) menyatakan bahwa salah satu permasalahan dalam pembelajaran di sekolah adalah pola pembelajaran yang diterapkan oleh guru tidak sesuai dengan karakteristik materi dan lebih banyak menggunakan metode ceramah. Fazilah (2015:49) juga menyatakan "dalam proses pembelajaran kebanyakan guru masih menggunakan metode konvensional yang hanya menggunakan buku ajar sebagai resep yang siap diberikan kepada siswa dan hanya mendengar dan mencatat saja." Senada dengan hal tersebut, Wati (2014) menyebutkan beberapa permasalahan dalam pembelajaran kimia khususnya pada materi koloid, yaitu (1) Guru menganggap bahwa materi sistem koloid yang diberikan di SMA dapat dibaca sendiri oleh siswa tanpa panduan sehingga siswa cenderung sulit mengingatnya dan menerapkannya dalam kehidupan sehari-hari jika tidak ada prakteknya; (2) Siswa sulit membedakan partikel-partikel koloid karena pada proses pembelajaran tidak memberikan percobaan, guru hanya menyampaikan materi saja; (3) Sifat-sifat koloid sulit dimengerti oleh siswa karena hampir tidak diamati secara nyata atau bersifat abstrak; (4) Dalam pembuatan koloid tidak dapat dipraktekkan semuanya karena fasilitas yang digunakan sangat terbatas; (5) Model pembelajaran yang sering digunakan model pengajaran ekspositori dengan metode ceramah. Selain itu masalah pembelajaran juga berasal dari siswa, yang meliputi masalah minat dan motivasi belajar, kemampuan menyimak bacaan, kemampuan bertanya, kemampuan merumuskan masalah, disiplin, etiket, dan kecenderungan untuk meperoleh hasil instan (Subagia \& Wiratma, 2017).

Penerapan strategi pembelajaran ekspositori atau strategi pembelajaran konvensional yang masih berpusat pada guru menyebabkan kurang berkembangnya kemampuan siswa dalam memecahkan masalah. Siswa juga terbiasa untuk menerima begitu saja apa yang dijelaskan guru tanpa adanya motivasi untuk belajar lebih jauh. Berdasarkan wawancara yang dilakukan peneliti terhadap enam guru kimia yang mengajar di kelas XI, ditemukan bahwa siswa kurang termotivasi untuk mencari sendiri dan cenderung cepat melupakan materi pelajaran yang sudah mereka pelajari. Hal ini mengakibatkan hasil belajar kimia siswa cenderung rendah.

Dengan demikian, perlu adanya strategi pembelajaran inovatif, yang dapat meningkatkan motivasi belajar dan memungkinkan siswa untuk menemukan sendiri pengetahuan yang harus 
mereka miliki. Subagia dan Wiratma (2017) juga menyatakan bahwa masalah metode pembelajaran, partisipasi siswa dalam pembelajaran, motivasi dan minat siswa, disiplin siswa dalam belajar, penguasaan konsep, dan penguasaan perhitungan kimia harus dipecahkan secara terintegrasi melalui pengembangan strategi yang tepat. Strategi pembelajaran kimia SMA berbasis percobaan awal merupakan salah satu strategi pembelajaran inovatif yang berpusat pada siswa. Strategi ini mengombinasikan model pendekatan percobaan awal yang dikembangkan oleh Shconner (1996) dengan siklus belajar dari Lawson. (1989). Namun strategi ini masih dalam tahap pengembangan sehingga perlu dilakukan penelitian eksperimen untuk melihat pengaruh strategi ini terhadap hasil belajar bila diterapkan pada materi kimia di beberapa sekolah dengan karakteristik populasi yang berbeda. Pada penelitian ini strategi pembelajaran kimia SMA berbasis percobaan awal diterapkan pada materi koloid di SMA Negeri 1 Baturiti.

\section{METODE}

Jenis penelitian ini adalah quasi experiment (eksperimen semu). Penelitian ini menggunaan rancangan nonrandomized control group pretest-postest design (Ary, dkk., 2010). Penelitian ini dilaksanakan di SMA Negeri 1 Baturiti yang beralamat di desa Perean, kecamatan Baturiti, kabupaten Tabanan. Populasi pada penelitian ini adalah kelas XI IPA di SMA Negeri 1 Baturiti tahun ajaran 2017/2018. Terdapat tiga kelas XI dengan jumlah total 71 orang siswa. Sampel dalam penelitian ini adalah siswa kelas XI IPA 2 dan XI IPA 3 SMA Negeri 1 Baturiti. Teknik pengambilan sampel yang digunakan adalah teknik cluster random sampling. Untuk memilih sampel dilakukan pengundian dan didapatkan dua kelas yaitu kelas XI IPA 2 dan XI IPA 3. Kemudian, pemilihan kelas eksperimen dan kontrol dilakukan dengan pengundian sehingga didapatkan kelas XI IPA 2 sebagai kelas eksperimen dan kelas XI IPA 3 sebagai kelas kontrol.

Metode pengumpulan data yang digunakan dalam penelitian ini adalah metode tes. Tes yang digunakan terdiri dari delapan soal pilihan ganda dan dua soal uraian. Pengujian instrument yang dilakukan meliputi uji validitas butir soal, reliabilitas, tingkat kesukaran, dan daya beda. Berdasarkan hasil uji coba validitas butir soal pilihan ganda, dari 13 butir soal pilihan ganda, delapan soal dinyatakan valid sedangkan lima soal lainnya dinyatakan tidak valid. Semua soal yang valid digunakan sebagai intrumen penliaian hasil belajar kognitif pada penelitian ini. Berdasarkan hasil uji coba validitas butir soal uraian, dari 7 butir soal uraian, tiga soal dinyatakan valid sedangkan lima soal lainnya dinyatakan tidak valid. Dua dari tiga soal yang valid dengan koefisien korelasi tertinggi digunakan sebagai intrumen penliaian hasil belajar kognitif pada penelitian ini. Soal pilihan ganda yang telah dinyatakan valid kemudian diuji reliabilitasnya dan menghasilkan koefisien reliabilitas sebesar 0,7285. Dengan demikian, reliabilitas soal pilihan ganda tergolong tinggi. Soal uraian yang telah dinyatakan valid kemudian diuji reliabilitasnya dan menghasilkan koefisien reliabilitas sebesar 0,9441. Dengan demikian, reliabilitas soal uraian tergolong sangat tinggi. Berdasarkan perhitungan tingkat kesukaran butir soal didapatkan hasil bahwa empat soal pilihan ganda tergolong mudah, empat soal pilihan ganda lainnya tergolong sedang, dan kedua soal uraian tergolang sukar. Berdasarkan hasil perhitungan daya beda butir soal pilihan ganda dan uraian, didapatkan bahwa dari delapan soal pilihan ganda, empat soal memiliki daya beda yang cukup, satu soal dengan daya beda baik, dan tiga soal dengan daya beda sangat baik. Daya beda kedua soal uraian masing-masing tergolong baik dan sangat baik.

Teknik analisi data yang digunakan dalam penelitian ini adalah statistik deskriptif dan statistik inferensial. Analisis dengan statistik deskriptif disajikan dalam bentuk data kecenderungan pusat, sebaran data, Tabel distribusi hasil pretest dan posttest, serta poligon. Statistik inferensial yang digunakan adalah Anakova dengan uji prasyarat yang meliputi uji normalitas, homogenitas, keberartian arah regresi dan linearitas regresi. Pengolahan data hasil pretest dan posttest dengan teknik analisis statistik inferensial dilakukan dengan bantuan aplikasi SPSS versi 16.0 for winjdows.

\section{HASIL DAN PEMBAHASAN}

Nilai rata-rata pretest kelas eksperimen lebih rendah dari kelas kontrol yaitu 29,3 berbanding 32,3 . Nilai rata-rata posttest kelas eksperimen lebih tinggi dari kelas kontrol yaitu 57,7 berbanding 54,2. Data nilai posttest dikelompokkan menjadi lima kategori yaitu sangat rendah, rendah, sedang, tinggi, dan sangat tinggi. Klasifikasi data posttest dapat dilihat pada Tabel 1.

Tabel 1

Distribusi Hasil Posttest Siswa

\begin{tabular}{cccc}
\hline \multirow{2}{*}{ Kriteria } & \multirow{3}{*}{ Klasifikasi } & \multicolumn{2}{c}{ Kelas Eksperimen } \\
& & Frekuensi & Persentase \\
\hline $80 \leq \mathrm{X}$ & Sangat & 2 & $8,33 \%$
\end{tabular}




\begin{tabular}{|c|c|c|c|}
\hline & Baik & & \\
\hline $\begin{array}{c}60 \leq X \\
<80\end{array}$ & Baik & 8 & $33,33 \%$ \\
\hline $\begin{array}{c}40 \leq X \\
<60\end{array}$ & Sedang & 14 & $58,33 \%$ \\
\hline $\begin{array}{c}20 \leq X \\
<40\end{array}$ & Kurang & 0 & $0 \%$ \\
\hline$x<20$ & $\begin{array}{l}\text { Sangat } \\
\text { Kurang }\end{array}$ & 0 & $0 \%$ \\
\hline \multirow{2}{*}{ Kriteria } & \multirow{2}{*}{ Klasifikasi } & \multicolumn{2}{|c|}{ Kelas Kontrol } \\
\hline & & Frekuensi & Persentase \\
\hline $80 \leq X$ & $\begin{array}{l}\text { Sangat } \\
\text { Baik }\end{array}$ & 0 & $0 \%$ \\
\hline $\begin{array}{c}60 \leq X \\
<80\end{array}$ & Baik & 0 & $0 \%$ \\
\hline $\begin{array}{c}40 \leq X \\
<60\end{array}$ & Sedang & 9 & $37,50 \%$ \\
\hline $\begin{array}{c}20 \leq X \\
<40\end{array}$ & Kurang & 14 & $58,33 \%$ \\
\hline$x<20$ & $\begin{array}{l}\text { Sangat } \\
\text { Kurang }\end{array}$ & 1 & $4,17 \%$ \\
\hline
\end{tabular}

Berdasarkan Tabel 1 dapat dilihat bahwa sebagian besar nilai posttest kelas eksperimen dan kontrol tergolong rendah dan sedang. Sebagian kecil kelas eksperimen memiliki nilai posttest yang tergolong tinggi dan sangat tinggi, sedangkan pada kelas kontrol tidak ada siswa yang memiliki nilai posttest yang tergolong tinggi dan sangat tinggi, bahkan terdapat satu siswa yang memiliki nilai posttest tergolong sangat rendah. Kedua kelompok siswa mengalami peninggkatan hasil belajar, namun peningkatan hasil belajar hingga tergolong tinggi dan sangat tinggi hanya terjadi pada kelas eksperimen. Grafik hasil pengelompokan nilai posttest kelas kontrol dan eksperimen dapat dilihat pada Gambar 1.

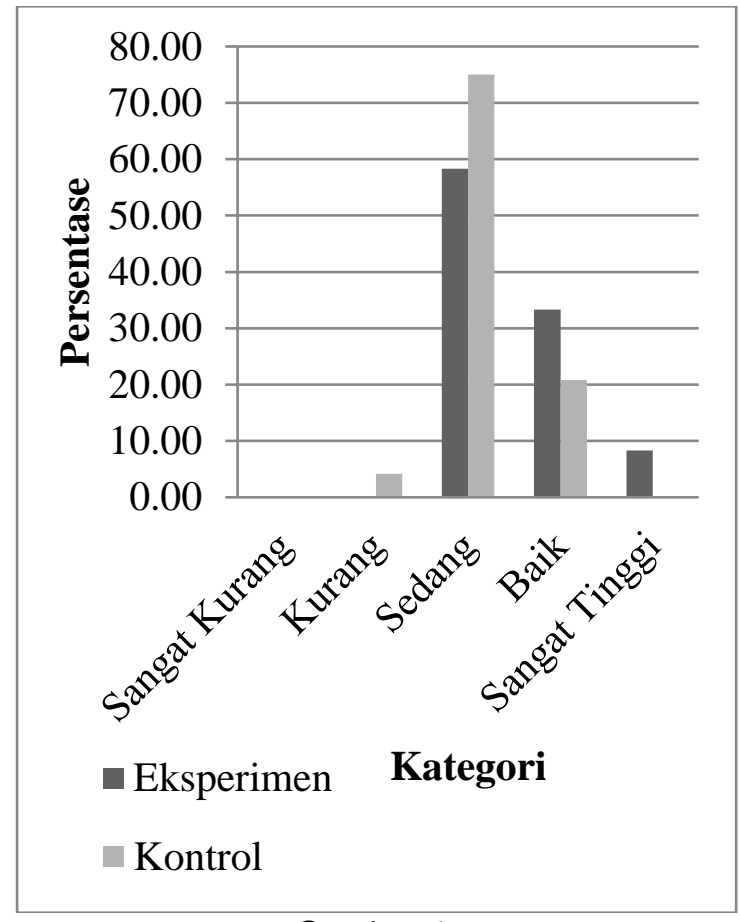

Gambar 1.

Grafik nilai posttest kelas kontrol dan eksperimen 
Berdasarkan grafik nilai posttest kelas eksperimen dan kontrol dapat dilihat bahwa kelas eksperimen memiliki hasil belajar yang lebih tinggi dari pada kelas kontrol. Nilai posttest kelas eksperimen tergolong rendah, sedang, tinggi dan sangat tinggi, sedangkan pada kelas kontrol nilai siswa tergolong sangat rendah, rendah, dan sedang. Persentase siswa dengan nilai posttest yang tergolong rendah juga lebih banyak berada di kelas kontrol.

Nilai pretest dan posttest kemudian dianalisis menggunakan statistik inverensial Anakova. Untuk itu, dilakukan uji normalitas, homogenitas, linearitas, dan kemiringan garis regeresi data sebagai uji asumsi penggunaan metode statistik Anakova. Semua pengujian asumsi yang dilakukan, menunjukkan bahwa asumsi telah terpenuhi sehingga dapat dilanjutkan ke tahap pengujian hipotesis.

Hasil uji hipotesis dengan Anakova menunjukkan bahwa terdapat perbedaan hasil belajar antara siswa yang dibelajarkan dengan strategi pembelajaran kimia berbasis percobaan awal dan strategi pembelajaran ekspositori dengan nilai $F$ sebesar 8,720 dengan signfikansi 0,005. Jadi dapat disimpulkan bahwa skor rata-rata hasil belajar siswa yang dibelajarkan dengan strategi pembelajaran kimia SMA berbasis percobaan awal dan yang dibelajarkan dengan strategi pembelajaran ekspositori berbeda secara signifikan pada taraf signifikansi 0,05.

\section{Pembahasan}

Berdasarkan analisis dengan statistik inferensial Anakova, diketahui bahwa terdapat perbedaan hasil belajar antara siswa yang dibelajarkan dengan strategi pembelajaran kimia SMA berbasis percobaan awal dan strategi pembelajaran ekspositori. Hal ini senada dengan penelitian yang dilakukan oleh Yasnia, dkk (2017) dan Nyeneng, dkk (2015) yang menemukan bahwa terdapat perbedaan hasil belajar antara siswa yang dibelajarkan dengan model starter experiment dengan siswa yang dibelajarkan dengan metode ekspositori atau model pembelajaran ekspositori. Selain itu, penelitian yang dilakukan oleh Sastra (2018) dan (Wahyuni 2018) juga menemukan bahwa terdapat perbedaan hasil belajar antara siswa yang belajar dengan strategi pembelajaran kimia SMA berbasis percobaan awal dan siswa yang belajar dengan strategi pembelajaran ekspositoris.

Pengetahuan awal siswa yang merupakan variabel kovariat diukur menggunakan pretest. Nilai rata-rata pretest kelas eksperimen lebih rendah dari kelompok kontrol yaitu 29,3 pada kelas eksperimen dan 32,3 pada kelompok kontrol. Hal ini menunjukkan bahwa pengetahuan awal kelas eksperimen lebih rendah dari pada kelompok kontrol sebelum diberikan perlakuan. Nilai pretest siswa dikendalikan dengan menggunakan metode statistik Anakova sehingga tidak mempengaruhi hasil belajar siswa (posttest) (Ary, 2010). Interaksi antara pretest dan strategi pembelajaran dapat dilihat pada hasil uji kemiringan garis regresi yang menunjukkan nilai signifikansi lebih besar dari 0,05 , dengan demikian dapat disimpulkan bahwa tidak ada interaksi antara nilai pretest dan strategi pembelajaran, sehingga perbedaan hasil belajar siswa hanya dipengaruhi oleh strategi pembelajaran tanpa adanya gangguan dari pengadaan pretest.

Kelas eksperimen dibelajarkan dengan strategi pembelajaran kimia SMA berbasis percobaan awal yang memungkinkan siswa untuk secara aktif menemukan sendiri pengetahuan yang harus mereka miliki. Sebanyak $33,33 \%$ siswa pada kelas eksperimen memiliki nilai posttest yang tergolong baik dan $8,33 \%$ siswa tergolong sangat baik, sedangkan pada kelompok kontrol, hanya $20,83 \%$ siswa yang tergolong baik dan tidak ada siswa yang memiliki nilai posttest yang dikategorikan sangat baik. Ini menunjukkan bahwa strategi pembelajaran kimia SMA berbasis percobaan awal cukup efektif untuk meningkatkan hasil belajar pada beberapa siswa.

Pada tahap observasi dalam strategi pembelajaran kimia SMA berbasis percobaan awal, siswa diberikan stimulus kompleks berupa demonstrasi eksperimen sederhana, kemudian siswa diminta untuk membuat hasil pengamatan secara individu, mendiskusikan dan menetapkan pengamatan yang disepakati secara klasikal, membuat pertanyaan sesuai dengan hasil pengamatan yang disepakati, mendiskusikan dan menetapkan pertanyaan yang disepakati secara klasikal, mencari jawaban dari pertanyaan secara berkelompok. Tahap ini merupakan tahap yang sangat penting karena pada tahap inilah sisiwa dilatih untuk berpikir, mencari tahu, dan mengemukakan pendapat, sehingga siswa terbiasa untuk melakukan pengumpulan data dan diskusi dalam proses pemecahan masalah. Pemberian stimulus kompleks dalam bentuk demonstrasi eksperimen sederhana, yang dalam penelitian ini adalah demostrasi percobaan efek Tyndall, dapat meningkatkann motivasi siswa untuk belajar lebih jauh tentang materi koloid. Bybee, dkk (2008) menyatakan bahwa demonstrasi yang diberikan di awal (inductive demonstration) dapat mendorong siswa untuk menganalisis dan membuat penjelasan sesuai dengan pengetahuan mereka. Inductive demonstration juga dapat meningkatkan motivasi siswa karena memberikan banyak teka-teki yang harus mereka pecahkan (Bybee, dkk., 2008). Siswa juga diberikan 
kesempatan untuk menuliskan hasil pengamatan, dan pertanyaan secara individu sebelum melakukan diskusi kelas dan diskusi kelompok. Dengan demikian, siswa menjadi lebih tertarik dalam mengikuti proses pembelajaran, karena mereka diikutsertakan dalam pembelajaran dan mendapatkan kesempatan untuk berpikir (Bybee, dkk., 2008). Pada kegiatan ini, siswa diberikan kesempatan untuk mencari sendiri serta mengonstruksi pengetahuan secara aktif.

Tahap kedua strategi pembelajaran kimia SMA berbasis percobaan awal adalah penemuan konsep. Pada tahap ini, siswa diberikan pertanyaan-pertanyaan yang berhubungan dengan istilah-istilah yang berkaitan dengan materi koloid. Tahap ini serupa dengan tahap pengenalan istilah pada silklus belajar Lawson. Lawson (1989:5) menyatakan bahwa,

tahap pengenalan istilah (term introduction) memungkinkan guru untuk mengenalkan istilah yang perlu diketahui siswa, dan sekaligus memberikan siswa kesempatan untuk menghubungkan pola pengetahuan yang telah dimiliki dengan istilah baru yang berkaitan dengan materi ajar.

Siswa diberikan LKS dan ditugaskan untuk menjawab pertanyaan-pertanyaan pada LKS secara berkelompok, kemudian mempresentasikannya di depan kelas. Dalam kegiatan ini, siswa dapat mengasah kemampuan mereka dalam berdiskusi dan mengemukakan pendapat. Siswa juga dapat mengonfirmasi pengetahuan yang mereka dapatkan melalui crosscheck antar kelompok. Tahap term introduction juga sering mengarahkan kepada jawaban terbaik dari pertanyaan konseptual yang diberikan karena siswa diberikan kesempatan untuk bekerja secara mandiri (Lawson, 1989).

Tahap ketiga pada strategi pembelajaran kimia SMA berbasis percobaan awal adalah penerapan konsep. Siswa diberikan tugas untuk mencari penjelasan tentang contoh penerapan atau kegunaan konsep koloid dalam kehidupan sehari-hari yang ada pada LKS. Nightingale dan O'Neil dalam Killen (2007) menyatakan bahwa pembelajaran berkualitas tinggi dapat terwujud ketika siswa dapat mengaplikasikan pengetahuannya untuk memecahkan masalah. Meski tidak memecahkan permasalahan yang ada disekitarnya secara ekspositori, siswa mencari sendiri contoh penerapan konsep yang telah mereka pelajari, sehingga mendapatkan pengetahuan yang utuh. Lawson (1989) menyatakan bahwa tahap penerapan konsep dapat memberikan kesempatan pada siswa untuk menggunakan istilah yang telah mereka dapatkan dan memungkinkan siswa untuk melakukan eksplorasi pola pengetahuan yang baru. Tahap ini juga memungkinkan siswa untuk mendapat pengalaman belajar bermakna. Belajar bermakna oleh Ausubel (dalam Schunk, 2012) menyatakan bahwa pembelajaran bermakna terjadi apabila pengetahuan baru yang didapatkan memiliki hubugan sistematik dengan konsep yang telah diketahui. Pembelajaran yang bermakna memungkinkan siswa untuk lebih memahami pengetahuan yang mereka dapatkan.

Kelompok kontrol pada penelitian ini, dibelajarkan dengan strategi pembelajaran ekspositori. Pertama, dilakukan persiapan oleh guru, kemudian guru mengarahkan perhatian siswa dengan pemberian informasi tentang tujuan pembelajaran dan orientasi pembelajaran berupa pemberian motivasi tentang sorot lampu mobil pada malam yang berkabut. Kegiatan ini dilakukan untuk mengarahkan siswa agar termotivasi dan fokus pada materi yang akan dibahas. Tahap berikutnya dalah penyajian materi pelajaran, siswa diberikan penjelasan tentang materi koloid yang meliputi perbedaan koloid dengan larutan dan suspensi, jenis-jenis koloid, sifat-sifat koloid, cara pembuatan koloid, dan kegunaan koloid. Tahap terakhir yaitu evaluasi dan pengaplikasian yaitu dengan memberikan kesempatan siswa untuk berlatih dilakukan dengan memberikan tugas pada siswa untuk menuliskan konsep-konsep yang telah mereka dapatkan pada LKS yang diberikan. Pertanyaan yang terdapat pada LKS sama dengan pertanyaan pada LKS penemuan konsep dan penerapan konsep 1 pada kelas eksperimen. Hal ini dilakukan agar siswa dapat mengingat kembali pengetahuan yang mereka dapatkan. Untuk pengaplikasian dilakukan percobaan tentang efek Tyndall dan latihan mandiri dengan memberikan tugas proyek berkelompok yaitu merancang, melakukan, dan melaporkan pembuatan koloid daluman.

Perbedaan hasil belajar antara kelas eksperimen dan kontrol disebabkan oleh strategi yang diterapkan, khususnya pada proses siswa mendapatkan pengetahuan tentang materi yang diajarkan. Pada kelas eksperimen, siswa mendapat pengetahuan melalui proses pencarian dan penemuan, sedangkan pada kelompok kontrol siswa mendapat pengetahuan dari informasi yang diberikan guru. Menurut teori belajar Burner proses penemuan menghasilkan proses belajar lebih baik karena siswa telah mengatur materi-materi dengan cara yang berguna dan hasilnya siswa menjadi pebelajar dan pemecah masalah yang lebih baik, karena siswa telah berlatih dalam memproses informasi (Mayer, 2008). Sedangkan, pada kelas kontrol pengetahuan siswa tergantung dari seberapa baik kemampuan siswa dalam menyimak dan mengingat (Killen, 2007), sehingga siswa yang kurang baik dalam menyimak dan mengingat akan mendapatkan hasil belajar yang lebih rendah. 


\section{SIMPULAN DAN SARAN}

Berdasarkan hasil penelitian dan pembahasan dapat dibuat simpulan bahwa terdapat perbedaan hasil belajar antara siswa yang dibelajarkan dengan strategi pembelajaran kimia SMA berbasis percobaan awal dan yang dibelajarkan dengan strategi pembelajaran ekspositori. Siswa yang belajar dengan strategi pembelajaran kimia SMA berbasis percobaan awal memiliki rata-rata hasil belajar kimia yang lebih tinggi dibandingkan siswa yang belajar dengan strategi pembelajaran ekspositori. Perbedaan hasil belajar ini disebabkan oleh perbedaan strategi pembelajaran yang digunakan. Pada strategi pembelajaran kimia SMA berbasis percobaan awal siswa diberikan stimulus kompleks berupa demonstrasi percobaan sederhana yang dapat meningkatkan motivasi belajar siswa, sedangkan pada strategi pembelajaran ekspositori tidak. Keterampilan berpikir siswa pada kelas eksperimen juga berkembang karena mereka diharuskan untuk terlibat aktif dalam diskusi kelas dan diskusi kelompok. Dengan demikian, siswa dapat membangun pemahaman sendiri secara aktif dan mendapatkan pengalaman belajar yang bermakna. Keterlibatan siswa dalam proses penemuan dapat meningkatkan pengetahuannya dan meminimalkan pembelajaran dengan cara menghapal.

Berdasarkan temuan-temuan yang telah dipaparkan, implikasi hasil penelitian ini sebagai berikut. (1) Penerapan strategi pembelajaran kimia SMA berbasis percobaan awal menuntut adanya kemampuan yang tinggi dalam mengelola kelas dan memimpin diskusi. Dengan demikian, kegiatan diskusi dapat berjalan lebih efektif dan tidak hanya didominasi oleh siswa dengan kemampuan intelegensi yang tinggi. (2) Penerapan strategi pembelajaran kimia SMA berbasis percobaan awal juga menuntut adanya persiapan yang matang terutama dalam mempersiapkan percobaan awal dan mengelola pembelajaran pada tahap observasi. Percobaan awal yang didemonstrasikan hendaknya merupakan percobaan yang simpel dan mengarahkan siswa pada inti materi yang akan dipelajari. Selain mempersiapkan percobaan awal, guru harus mampu mengarahkan siswa kepada jawaban atau pertanyaan yang diinginkan sehingga diskusi kelas dan diskusi kelompok tidak melenceng dari tujuan pembelajaran. (3) Dalam mempersiapkan percobaan awal, juga diperlukan kreatifitas lebih untuk memodifikasi alat agar percobaan sederhana yang didemonstrasikan dapat diamati oleh seluruh siswa yang ada di dalam ruangan kelas.

\section{DAFTAR RUJUKAN}

Ary, D., Lucy C.J., Chris S., dan Asghar R., 2010. Introduction to Research in Education. Edisi ke-8. Canada: Wadsworth Cengage Learning.

Bybe, R.W., Janet C.P,. dan Leslie W.T., 2008. Teaching Secondary School Science: Strategy for Developing Scientific Literacy. Edisi ke-9. New Jersey: Pearson Merrill Prentice Hall.

Fazilah, Z., 2015. "Pengaruh Model Pembelajaran NHT dengan Menggunakan Makromedia Flash pada Materi Sistem Koloid Terhadap Hasil Belajar Siswa MAN Krueng Geukueh". Jurnal Pendidikan dan Teknologi Informasi, Volume 1,

Killen, R., 2007. Efective Teaching Strategies. Edisi ke-4. Australia: Cengage Learning.

Lawson, A. E.,Michael R. A, dan John W.R, 1989. A Theory ofInstruction: Using The Learning Cycleto Teach Science Concepts and Thinking Skills. s.I.:NARST MONOGRAPH.

Mayer, R. E., 2008. Learning and Instruction. Ohio: Pearson Merrill Prentice Hall.

Merta, L. M., 2013. "Pengaruh Model Pembelajaran Kontekstual terhadap Penguasaan Konsep Koloid dan Sikap Ilmiah Siswa". Jurnal Pendidikan dan Pengajaran, Volume 46, Nomor 1 (hlm. 9-19).

Nyeneng, I. K., Lasmawan, I. W., dan Dantes, N. (2015). "Pengaruh Model Pendekatan Starter Eksperimen (PSE) Terhadap Keterampilan Proses Sains Dan Hasil Belajar Sains Siswa SD Gugus VIII Kecamatan Abang". PENDASI: Jurnal Pendidikan Dasar Indonesia. Volume 5, Nomor 1 (hlm. 1-10).

Sari, S. M., Sartika, R. P., dan Fitriani, F., 2017. "Pengaruh Model Siklus Belajar 5E pada Praktikum Koloid terhadap Hasil Belajar Siswa Kelas XI MIA SMA Negeri 2 Pontianak". AR-RAZI Jurnal Ilmiah. Volume 5, Nomor 1 (hlm. 1-8).

Sastra, I N. E. S. D., 2018. Pengaruh Strategi Pembelajaran Kimia SMA Berbasis Percobaan Awal terhadap Hasil Belajar di SMA Negeri 2 Negara. Skripsi (tidak diterbitkan). Jurusan Kimia, Universitas Pendidikan Ganesha.

Schonherr, J., 1996. "The Starter Experiment Approach (SEA) to Teaching Chemistry and Physics in The Phillippines and Indonesia and The Rest od The World". Science Education International, Volume 7, Nomor 4 (hlm 29-33).

Schunk, D. H., 2012. Learning Theories: An Edcational Perspective. Boston: Pearson. 
Subagia, I W. dan I G.L. Wiratma. 2017. Pengembangan Strategi Pembelajaran Kimia SMA Berbasis Percobaan. Laporan Akhir Penelitian Produk Terapan. Singaraja: Universitas Pendidikan Ganesha.

Subamia, I. D. P., 2012. "Keterampilan Proses Sains dan Hasil Belajar Siswa pada Pembelajaran Menggunakan Pendekatan Starter Experiment". Jurnal Pendidikan dan Pengajaran. Volume 45. Nomor 1 (hlm 27-37).

Peraturan Menteri Pendidikan dan Kebudayaan Nomor 22 Tahun 2016 tentang Standar Proses

Wahyuni, M. T., 2018. Pengaruh Strategi Pembelajaran Kimia SMA Berbasis Percobaan Awal terhadap Hasil BelajarKimia Siswa kelas XI di SMA Negeri 1 Sukasada. Skripsi (tidak diterbitkan). Jurusan Kimia, Universitas Pendidikan Ganesha.

Wati, R. dan Rusmansyah, A. S., 2014. "Meningkatkan Kemampuan Berpikir Kritis dan Hasil Belajar Siswa Kelas XI IPA 2 SMA PGRI 4 Banjarmasin pada Konsep Sistem Koloid". QUANTUM, Jurnal Inovasi Pendidikan Sain, Volume 5, Nomor 2 (hlm. 20-31).

Yasnia, T. M., Melati, H. A., dan Sartika, R. P. (2017). "Pengaruh Model Starter Eksperimen terhadap Aktivitas dan Hasil Belajar Siswa pada Materi Koloid". Jurnal Pendidikan dan Pembelajaran. Volume 6, Nomor 3 (hlm. 1-11). 